\title{
Développement des réseaux de médecins en Suisse
}

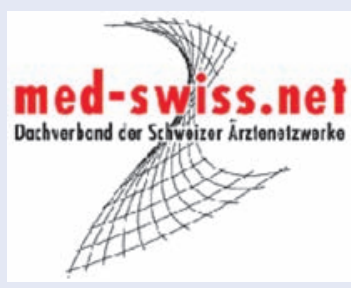

\section{L'organisation faîtière des réseaux de médecins suisses med-swiss.net compte} 38 associations de médecins de famille ainsi que des réseaux regroupant plus de 1500 médecins en charge de 250000 assurés managed care. Ces réseaux appliquent le managed care tout en agissant de manière indépendante sur le plan opérationnel; I'association faîtière assume des tâches stratégiques.

Comité med-swiss.net

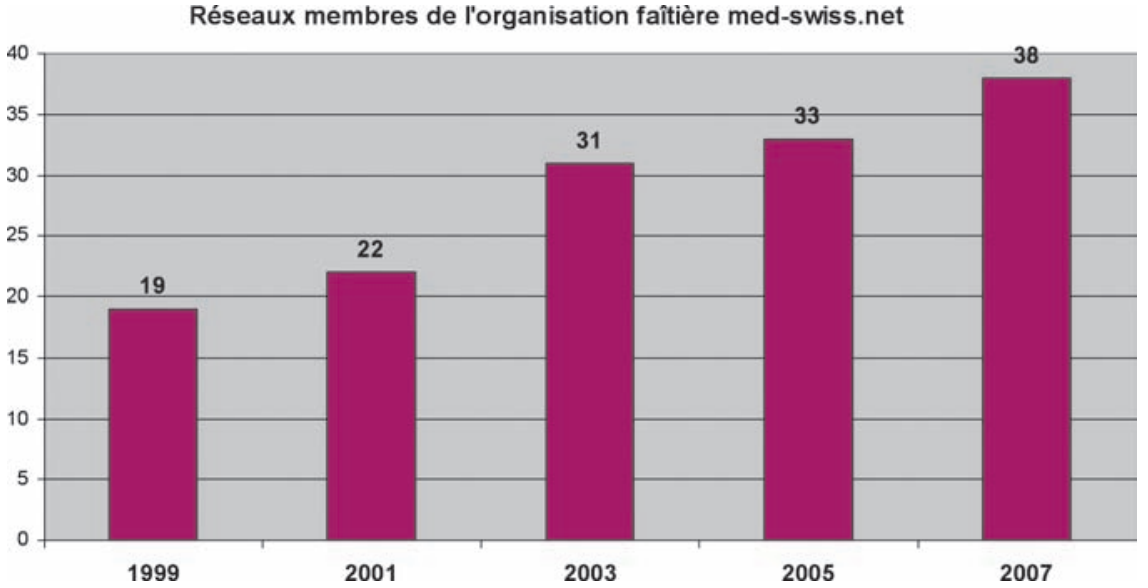

\section{Pourquoi des réseaux de médecins?}

La santé publique se caractérise par:

- une demande non contrôlée;

- une offre non contrôlée;

- des ressources financières de plus en plus limitées;

- une utilité mal documentée sur le plan économique (à l'exception de la SUVA qui établit une statistique des frais de guérison et des indemnités journalières).

\section{Solution: le managed care}

Avec le managed care, il est possible:

- d'harmoniser soigneusement l'offre et la demande en tenant compte des ressources;

- de gérer toute la chaîne thérapeutique (ambulatoire et hospitalière);

- d'attester l'efficacité, l'adéquation et l'économicité des prestations (critères EAE selon la LAMal).

Le managed care se développera avec ou sans le corps médical!
- Qui d'autre pourrait mieux juger l'efficacité, l'adéquation et avant tout l'économicité des prestations médicales que le corps médical lui-même?

- Le critère de l'économicité peut, notamment, mieux être attesté par un réseau de médecins que par des médecins agissant individuellement.

\section{Qu'est-ce qu'un réseau de médecins?}

- Les réseaux de médecins sont formés par des professionnels fournissant des prestations de santé adaptées aux besoins des patients dans le cadre d'un processus thérapeutique convenu, de structures organisationnelles entrepreneuriales et d'une culture de soins commune. Ces médecins collaborent éventuellement avec des fournisseurs de prestations et des assureurs non rattachés au réseau.

- Les réseaux de médecins sont prêts à assumer une coresponsabilité économique.

- Les patients sont pris en charge selon des critères de qualité et de coûts vérifiables. Grâce à des traitements ambulatoires prodigués de façon optimale, il est possible d'économiser des coûts d'hospitalisation élevés.

- Une forme de communication structurée donne une large assise à la prise de responsabilité (cercles de qualité, CIRS).

Adhérez, vous aussi, à un réseau de médecins; vous pouvez également créer un nouveau réseau.

Vous pourrez ainsi évaluer vous-même l'économicité de votre activité médicale.

\section{Figure 1}

Développement du nombre de réseaux de médecins de 1999 à 2007. 